\title{
Correction: Barak, S. et al. “Long-Term Outcomes of Early Enzyme Replacement Therapy for Mucopolysaccharidosis IV: Clinical Case Studies of Two Siblings". Diagnostics 2020, 10, 108
}

\author{
Sharon Barak 1,2,*, Yair Anikster ${ }^{3,4,5}$, Ifat Sarouk ${ }^{6,7}$, Eve Stern ${ }^{8}$, Etzyona Eisenstein ${ }^{1}$, \\ Tamar Yissar ${ }^{1}$, Nir Sherr-Lurie ${ }^{9}$, Annick Raas-Rothschild ${ }^{10,11}$ and Dafna Guttman ${ }^{1}$ \\ 1 Department of Pediatric Rehabilitation, Edmond and Lily Safra Children's Hospital, Chaim Sheba Medical \\ Center, Ramat-Gan 5265601, Israel; Etzyona.Eisenstein@sheba.health.gov.il (E.E.); \\ Tamar.Yissar@sheba.health.gov (T.Y.); Dafna.Gutman@sheba.health.gov.il (D.G.) \\ 8 Pediatric Endocrine and Diabetes Unit, Chaim Sheba Medical Center, Edmond and Lily Safra Children's \\ Hospital, Ramat-Gan 5265601, Israel; zipporaheve.stern@sheba.health.gov.il \\ 9 Pediatric Orthopedic Unit, Edmond and Lilly Safra Children Hospital, Chaim Sheba Medical Center, \\ Ramat Gan 5265601, Israel; Nir.Sherr@sheba.health.gov.il \\ 10 Institute of Rare Diseases, Edmond and Lily Safra Children's hospital, Chaim Sheba Medical Center, \\ Ramat Gan 5265601, Israel; Annick.Rothschild@sheba.health.gov.il \\ 11 The Sackler Faculty of Medicine, Tel Aviv University, Tel Aviv postcode Israel, Ramat Aviv 69978, Israel \\ * Correspondence: sharoni.baraki@gmail.com
}

The authors wish to make the following correction to this paper [1]:

In the first paragraph of the Results section: "P1 and P2 started ERT with elosulfase alfa (VIMIZIM ${ }^{\circledR}$ by BioMarin(C) 5 months post-diagnosis at age 4.5 years and 11 months, respectively, with an intravenous dose of $1.0 \mathrm{mg} / \mathrm{kg} /$ week." The value of the dose is $1.0 \mathrm{mg} / \mathrm{kg} /$ week but should be corrected to $2.0 \mathrm{mg} / \mathrm{kg} /$ week.

These changes have no material impact on the conclusions of our paper. We apologize to our readers.

\section{Reference}

1. Barak, S.; Anikster, Y.; Sarouk, I.; Stern, E.; Eisenstein, E.; Yissar, T.; Sherr-Lurie, N.; Raas-Rothschild, A.R.; Guttman, D. Long-Term Outcomes of Early Enzyme Replacement Therapy for Mucopolysaccharidosis IV: Clinical Case Studies of Two Siblings. Diagnostics 2020, 10, 108. [CrossRef] [PubMed]

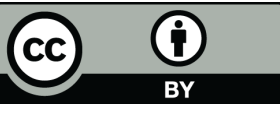

(C) 2020 by the authors. Licensee MDPI, Basel, Switzerland. This article is an open access article distributed under the terms and conditions of the Creative Commons Attribution (CC BY) license (http://creativecommons.org/licenses/by/4.0/). 